\title{
The times they are a-changin': The evolution of prostate cancer screening practices and beliefs among primary care physicians in Victoria, British Columbia
}

\author{
Jesse Spooner, $\mathrm{MD}^{1}$; Manjot Birk, $\mathrm{BSc}^{2}$; Victor Espinosa, $\mathrm{MSc}^{3}$; Nathan Hoag, MD, FRCSC \\ ${ }^{1}$ Department of Urology, Dalhousie University, Halifax, NS, Canada; ${ }^{2}$ Island Medical Program, University of \\ British Columbia, Victoria, BC, Canada; ${ }^{3}$ Island Health, Victoria, Department of Research and Capacity, Victoria, \\ BC, Canada; ${ }^{4}$ Department of Urological Sciences, University of British Columbia, Victoria, BC, Canada
}

Cite as: Spooner J, Birk M, Espinosa V, et al. The times they are a-changin': The evolution of prostate cancer screening practices and beliefs among primary care physicians in Victoria, British Columbia. Can Urol Assoc J 2020 November 17; Epub ahead of print. http://dx.doi.org/10.5489/cuaj.6680

Published online November 17, 2020

$* * *$

\section{Abstract}

Introduction: Prostate cancer screening practices remain controversial among primary care practitioners (PCPs). Inconsistent guidelines and publication of large prostate cancer screening trials have failed to provide definitive guidance. This study investigates the evolution of prostate cancer screening practices and beliefs over 12 years, in Victoria, British Columbia.

Methods: Questionnaires were delivered to 119 randomly selected PCPs in 2019. Descriptive analysis together with exploratory graphs and Pearson Chi-squared test for independence was calculated. The 2008 data was compared by determining if their value fell within the 2019 data's 95\% confidence interval.

Results: Response rate was $69.8 \%$ (83/119); 30.1\% of PCPs reported regularly screening asymptomatic men with prostate-specific antigen (PSA) testing and $37.3 \%$ reported regularly performing digital rectal exam (DRE). The combination of PSA and DRE was the most commonly used (48.2\%) screening modality. Most (73.5\%) reported that guidelines influence their screening practices, with the most popular choice being those published by The Canadian Task Force on Preventive Health Care (CTF) (32.5\%).

Conclusions: The results demonstrate a movement away from prostate cancer screening among PCPs when compared to 2008. PCPs believe that DRE and PSA are less valuable as screening tools and that there is insufficient evidence to support their use. The most used initial screening modality was the combination of PSA/DRE, however, we found a decrease in their use between the two study periods. Clinical guidelines continue to influence PCPs screening practices, but the 
shift of more PCPs following the CTF guidelines since 2008 has likely led to the reciprocal decrease in prostate cancer screening.

\section{Introduction}

Cancer of the prostate is the most commonly diagnosed non-cutaneous cancer in Canadian men and the third leading cause of deaths due to cancer in Canada. ${ }^{1}$ In 2020, it is estimated that 23,300 men will be diagnosed with prostate cancer. ${ }^{1}$

A meta-analysis in 2003 demonstrated the pooled sensitivity for prostate specific antigen (PSA) in relation to prostate cancer was $72.1 \%$ with a $93.2 \%$ specificity, while a 2018 metaanalysis demonstrated the pooled sensitivity for digital rectal examination (DRE) had 53.2\% sensitivity, and $83.6 \%$ specificity. ${ }^{2-4}$ The Canadian Urological Association (CUA) suggests men undergoing prostate cancer screening should have DRE and PSA testing, as it has been suggested that DRE may help detect significant disease. ${ }^{5-8}$

There has been controversy and uncertainty about optimal prostate cancer screening practices for many years. A 2017 national survey determined that 55.6\% of Canadian PCPs feel that risk of PSA screening outweighs the benefits, while an Ontario survey found that $72.6 \%$ of respondents feel PSA screening leads to overdiagnosis and treatment. ${ }^{4,9}$ Due to the potential issues with overdiagnosis, The U.S. Preventive Services Task Force (USPSTF) advised against screening men over 75 years of age with the PSA test in 2008, and the Canadian Task Force on Preventive Health Care (CTF) followed in 2014, by recommending against screening asymptomatic, healthy men of any age. ${ }^{10-13}$ There exists discrepancy amongst screening recommendations from health organizations which may have led to diverse prostate cancer screening practices among PCPs (Appendix 1).

Hoag et al., ${ }^{14}$ performed a study in 2008 to survey PCP attitudes and beliefs towards prostate cancer screening, in Victoria, British Columbia (BC). It was identified that guidelines influenced primary care practice. However, there was little agreement among the respondents of the most appropriate prostate cancer screening standard of care. ${ }^{14}$ Since the time of the 2008 publication, new data has emerged from large screening trials (PLCO, ERSPC, and the Goteborg study), as well as guideline updates (Appendix 1) ${ }^{15-18}$ This study aims to compare the evolution of attitudes and practices of prostate cancer screening among PCPs in Victoria, BC over a 12year period.

\section{Methods}

A questionnaire initially designed in 2008 by Hoag et al. ${ }^{14}$ was used in this study, with permission. The survey contained grouped questions according to respondent demographics, and attitudes on prostate cancer and prostate cancer screening practices. The survey included "choose one of the following," Likert scale, and "check all that apply" questions (Appendix 2). 
After obtaining institutional ethics review board approval, the BC College of Physicians and Surgeons database was used to identify a pool of 436 PCPs in Victoria, B.C. 436 PCPs were randomly assigned an integer value between 1 and 436. 250 integers between 1 and 436 were selected via random number generator, and those PCPs with the corresponding integer were chosen for the study. The list of 250 PCPs was refined by excluding PCPs who were primarily hospital-based, focused on women's health or recently retired/moved. A total of 119 surveys were hand delivered and completed surveys were returned via fax or email. The methods selection and randomization were kept identical to the 2008 study to minimize variation and confounding variables.

Survey data was analyzed using REDCap version 8.10.22 and SPSS version 25. This was a descriptive analysis including central tendency statistics, standard deviations and chi-square tests for each survey question to summarize the findings.

\section{Results}

Response rate was $69.8 \%$ (83/119). The mean age of PCPs who responded was 51 years (SD 11.62 ), while the mean years in practice was 22.2 years (SD 11.51 years). PCP demographics between this study and Hoag et al ${ }^{14}$ such as gender, age group and years in practice were not statistically significant (Table 1). Demographic information is summarized in Table 1.

The survey results show for screening asymptomatic men for prostate cancer using PSA testing, 9.6\% of respondents "always" screen, $20.5 \%$ reported "usually" and 51.8\% stated they "sometimes" screened. Also, the results show those who stated they screen for prostate cancer using PSA testing, $73.1 \%$ began at the age of 50 and $17.9 \%$ at the age of 40 . DRE was "always" used for prostate cancer screening by $37.3 \%$ of respondents, "usually" performed by $30.1 \%$, and "sometimes" used by $31.3 \%$. Only $1.2 \%$ stated they "rarely" performed DRE for prostate cancer screening. Additionally, those performing DRE for prostate cancer screening, $72.0 \%$ of respondents began at the age of 50, and $19.5 \%$ at the age of 40 . The preferred initial prostate cancer screening method by respondents is shown in Figure 1.

A total of $63.9 \%$ of respondents felt that DRE is a valuable tool for prostate cancer screening. $43.3 \%$ felt that PSA testing is valuable for prostate cancer screening, with $36.1 \%$ being undecided and $20.5 \%$ believing PSA is not a valuable tool. $32.5 \%$ stated there was insufficient evidence to support using DRE, and $49.4 \%$ felt that there was insufficient evidence to support using PSA testing for prostate cancer screening. $48.2 \%$ of respondents believe that BC Medical Services Plan (MSP) should pay for PSA testing for prostate cancer screening. $73.5 \%$ of respondents reported that clinical guidelines and recommendations influence their prostate cancer screening practices, with the most preferred guidelines published by the Canadian Task Force on Preventive Health Care (32.5\%), followed by the BC Cancer Agency (Figure 2). 
There was no significant correlation between physician age and the influence of guidelines on screening practices. There was no significant correlation between PCP gender, age, or years of practice and prostate cancer screening practices.

\section{Discussion}

Our survey responses indicate that PCPs in Victoria, BC are less likely to screen asymptomatic men for prostate cancer when compared to 2008 . Hoag et al. ${ }^{14}$ found that $92.4 .0 \%$ of PCPs surveyed were in favor of DRE screening asymptomatic men. In contrast, our study noted only $67.4 \%$ of PCPs regularly performing DRE screening (p-value $<0.001$ ).

Since 2008, there has been a statistically significant increase of PCPs who believe there is insufficient evidence to support PSA and DRE for prostate cancer screening from $33.8 \%$ to $49.4 \%$ and $8.2 \%$ to $32.5 \%$ of respondents, respectively. (p-value $<0.001$ ). Also, there has been a significant decrease in PCPs who feel PSA testing is valuable from $72.6 \%$ in 2008 to $43.3 \%$ in 2019 (p-value $<0.001$ ). A similar decrease is noted in for DRE screening as only $63.9 \%$ of PCPs in 2019 feel DRE is valuable for prostate cancer screening from $90.8 \%$ in 2008 (P value $<0.001$ ). Hoag et $\mathrm{al}^{14}$ noted that $47.9 \%$ of respondents began DRE screening for prostate cancer at age 40 in 2008 which dropped significantly to $19.5 \%$ in 2019 (p-value $<0.001$ ). $72.0 \%$ of respondents in 2019 began DRE screening at age 50 while only $46.6 \%$ did so in 2008 (p-value $<0.001$ ). This finding may represent a surrogate for the general attitude of moving away from prostate cancer screening for asymptomatic men by PCPs, and attitudes regarding the costs of PSA testing could partially account for the relative decrease in PSA screening compared to DRE. This may indicate that PCPs are less frequently using DRE and PSA for prostate cancer screening, and those that are screening appear to be starting at a later age.

Several limitations are noted in this study. Since the survey relied on self-reported data, those respondents who have stronger opinions may have been more likely to participate, therefore selection bias and disclosure bias could influence data. We surveyed one geographic area, and despite the response rate of $69.8 \%$, the sample size remains relatively small, making it difficult to extrapolate this data for all PCPs in British Columbia and Canada. In addition, response bias was also a possibility since the respondents were aware that local personnel were involved in the design of the survey.

Our results suggest a general movement away from prostate cancer screening in asymptomatic men among PCPs in Victoria, BC, and decreasing utilization of DRE and PSA testing. This trend may be a reflection of updated guidelines shifting away from routine prostate cancer screening in asymptomatic men. These results are in keeping with recent surveys across Canada and Ontario. ${ }^{4,9}$ What downstream effects occur from changing prostate cancer screening practices remain to be seen. 


\section{References}

1. Brenner DR, Weir HK, Demers AA, Ellison LF, Louzado C, Shaw A, Turner D, Woods RR, Smith LM. Projected estimates of cancer in Canada in 2020, CMAJ. 2020;192:E199205.

2. Mistry K, Cable G. Meta-analysis of prostate-specific antigen and digital rectal examination as screening tests for prostate carcinoma. J Am Board Fam Pract 2003;16:95-101. https://doi.org/10.3122/jabfm.16.2.95

3. Naji L, Randhawa H, Sohani Z, et al. Digital rectal examination for prostate cancer screening in primary care: A systematic Review and Meta-Analysis. Ann Fam Med 2018;16:149-54. https://doi.org/10.1370/afm.2205

4. Akerman J, Allard C, Tajzler C, et al. Prostate cancer screening among family physicians in Ontario: An update on attitudes and current practice. Can Urol Assoc J 2018;12:E53-8. http://dx.doi.org/10.5489/cuaj.4631

5. Rendon RA, Mason RJ, Marzouk K, et al. Canadian Urological Association recommendations on prostate cancer screening and early diagnosis. Can Urol Assoc J 2017;11:298-309. https://doi.org/10.5489/cuaj.4888

6. Okotie OT, Roehl KA, Han M, et al. Characteristics of prostate cancer detected by digital rectal examination only. Urology 2007;70:1117-20. https://doi.org/10.1016/j.urology.2007.07.019

7. Carvalhal GF, Smith DS, Mager DE, et al. Digital rectal examination for detecting prostate cancer at prostate-specific antigen levels of $4 \mathrm{ng} / \mathrm{ml}$ or less. J Urol 1999;161:8359. https://doi.org/10.1016/S0022-5347(01)61785-3

8. Gosselaar C, Roobol MJ, Roemeling S, et al. Screening for prostate cancer at low PSA range: The impact of digital rectal examination on tumour incidence and tumour characteristics. Prostate 2007;67:154-61. https://doi.org/10.1002/pros.20501

9. Goldenberg M, Skeldon S, Nayan M, et al. Prostate-specific antigen testing for prostate cancer screening: A national survery of Canadian primary care physicians' opinions and practices. Can Urol Assoc J 2017;11(12): 396-403. http://dx.doi.org/10.5489/cuaj.4486

10. Moyer VA, U.S. Preventive Services Task Force. Screening for Prostate Cancer: U.S. Preventive Services Task Force Recommendation Statement. Ann Intern Med 2012;157: 120-34. https://doi.org/10.7326/0003-4819-157-2-201207170-00459

11. US Preventive Services Task Force. Screening for Prostate Cancer: US preventive Services Task Force Recommendation Statement. JAMA 2018;319:1901-13. https://doi.org/10.1001/jama.2018.3710.

12. BC Cancer Agency. The pros and cons of PSA testing for prostate cancer. 2007. Available at http://www.bccancer.bc.ca/books/Documents/Genitourinary/PSAScreeningPatientPamph let2007April.pdf. Accessed Dec 01, 2019.

13. BC Cancer Agency. Prostate. 2019. Available at http://www.bccancer.bc.ca/healthinfo/types-of-cancer/mens-cancer/prostate. Accessed Dec 01, 2019.

14. Hoag N, Davidson R, Pommerville P. Prostate Cancer Screening practices and attitudes among primary care physicians in Victoria, British Columbia. BCMJ 2008;50:456-60.

15. Schroder FH, Hugosson J, Roobol MJ, et al. Screening and prostate cancer mortality: Results of the European Randomized Study of Screening for Prostate Cancer (ERSPC) at 
13 years of followup. Lancet 2014;384:2027-35. https://doi.org/10.1016/S01406736(14)60525-0

16. Pinsky PF, Prorok PC, Yu K, et al. Extended mortality results for prostate cancer screening in the PLCO trial with median followup of 15 years. Cancer 2017;123:592-9. https://doi.org/10.1002/cncr.30474

17. Hugosson J, Carlsson S, Aus G, et al. Mortality results from the Goteborg randomized, population-based prostate-cancer screening trial. Lancet Oncol 2010;11:725-32. https://doi.org/10.1016/S1470-2045(10)70146-7

18. Arnsrud Godtman R, Holmberg E, Lilja H, et al. Opportunistic testing vs. organized prostate-specific antigen screening: Outcome after 18 years in the Goteborg randomized, population-based prostate cancer screening trial. Eur Urol 2015;68:354-60. https://doi.org/10.1016/j.eururo.2014.12.006

19. Bell N, Connor Gorber S, Shane A, et al. Recommendations on screening for prostate cancer with the prostate-specific antigen test. Can Med Assoc J 2014;186:1225-34. https://doi.org/10.1503/cmaj.140703

20. Carter HB, Albertsen PC, Barry MJ, et al. Early detection of prostate cancer: AUA guideline. J Urol 2013;190:419-26. https://doi.org/10.1016/j.juro.2013.04.119

21. Mottet N, Bellmunt J, Bolla M, et al. EAU-ESTRO-SIOG guidelines on prostate cancer. Part 1: Screening, diagnosis, and local treatment with curative intent. Eur Urol 2017;71:618-29. https://doi.org/10.1016/j.eururo.2016.08.003

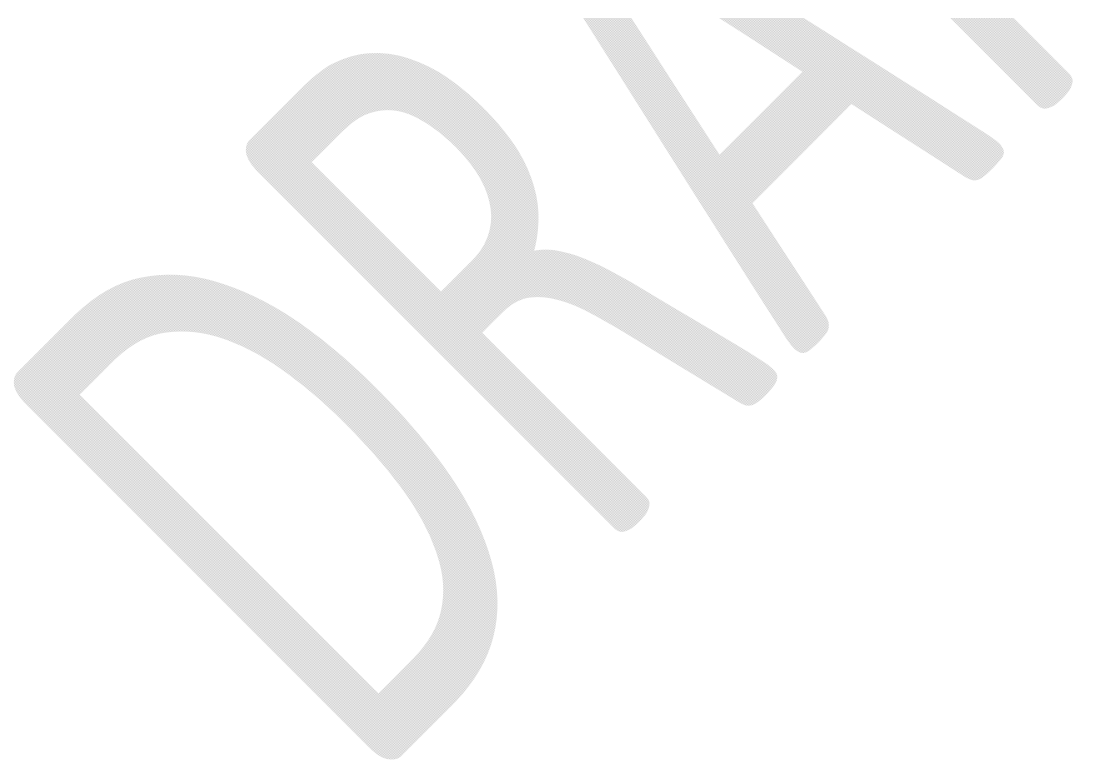




\section{Figures and Tables}

Fig. 1. Initial prostate cancer screening tool preferred by physicians surveyed. DRE: digital rectal exam; PSA: prostate-specific antigen.

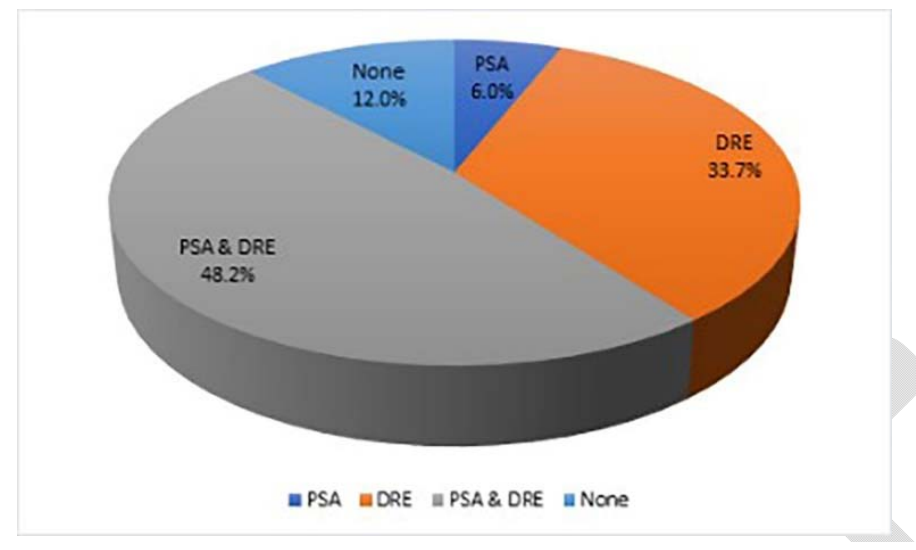

Fig. 2. A comparison of prostate cancer screening guidelines preferred by primary care physicians from 2008 to present. ${ }^{14}$ AUA: American Urological Association; BCCA: British Columbia Cancer Agency; CTF: Canadian Task Force on Preventive Health Care; CUA: Canadian Urological Association; EUA: European Urological Association; USPSTF: United States Preventive Services Task Force.

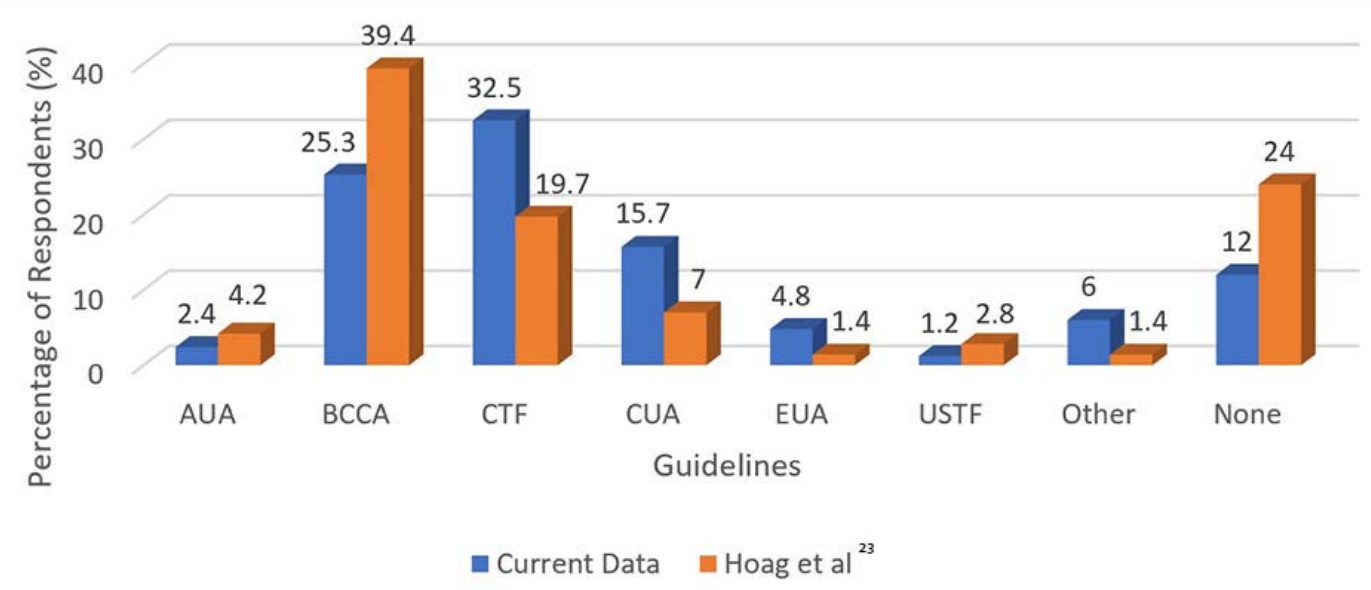




\section{Table 1. Respondent demographic comparison between 2008 and 2019}

\begin{tabular}{|c|c|c|c|c|c|c|c|c|}
\hline & & & \multicolumn{2}{|c|}{ Survey year } & \multirow[t]{2}{*}{ Total } & \multicolumn{3}{|c|}{ Pearson Chi-squared } \\
\hline & & & 2008 & 2019 & & Value & df & $\begin{array}{c}\text { Asymptotic } \\
\text { significance } \\
\text { (2-sided) }\end{array}$ \\
\hline \multirow[t]{4}{*}{ Gender } & Female & Count & 25 & 37 & 62 & $3.319^{\mathrm{a}}$ & 1 & 0.069 \\
\hline & & $\%$ within year & $31.6 \%$ & $45.7 \%$ & $38.8 \%$ & & & \\
\hline & Male & Count & 54 & 44 & 98 & & & \\
\hline & & $\%$ within year & $68.4 \%$ & $54.3 \%$ & $61.3 \%$ & & & \\
\hline \multirow{8}{*}{$\begin{array}{l}\text { Age } \\
\text { group }\end{array}$} & Less than 42 & Count & 13 & 19 & 32 & $5.988^{\mathrm{a}}$ & 3 & 0.112 \\
\hline & & $\%$ within year & $17.8 \%$ & $24.1 \%$ & $21.1 \%$ & 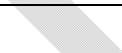 & & \\
\hline & $42-50$ & Count & 18 & 20 & 38 & 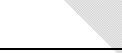 & & \\
\hline & & $\%$ within year & $24.7 \%$ & $25.3 \%$ & $25.0 \%$ & & & \\
\hline & $51-60$ & Count & 31 & 20 & 51 & & 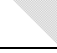 & \\
\hline & & $\%$ within year & $42.5 \%$ & $25.3 \%$ & $33.6 \%$ & & & 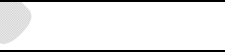 \\
\hline & $>60$ & Count & 11 & 20 & 31 & & & \\
\hline & & $\%$ within year & $15.1 \%$ & $25.3 \%$ & $20.4 \%$ & & & \\
\hline \multirow[t]{8}{*}{$\begin{array}{l}\text { Years in } \\
\text { practice }\end{array}$} & $<13$ & Count & 13 & 18 & 31 & $4.145^{\mathrm{a}}$ & 3 & 0.246 \\
\hline & & $\%$ within year & $16.5 \%$ & $22.5 \%$ & $19.5 \%$ & & & \\
\hline & $13-20$ & Count & 21 & 16 & 37 & & & \\
\hline & & $\%$ within year & $26.6 \%$ & $20.0 \%$ & $23.3 \%$ & & & \\
\hline & $21-30$ & Count & 31 & 24 & 55 & & & \\
\hline & 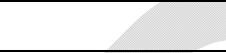 & $\%$ within year & $39.2 \%$ & $30.0 \%$ & $34.6 \%$ & & & \\
\hline & $>30$ & Count & 14 & 22 & 36 & & & \\
\hline & & $\%$ within year & $17.7 \%$ & $27.5 \%$ & $22.6 \%$ & & & \\
\hline
\end{tabular}




\begin{tabular}{|c|c|c|c|}
\hline Response & $\begin{array}{l}2008 \\
\text { value }\end{array}$ & $\begin{array}{c}2019 \\
\text { value }\end{array}$ & Chi-squared test $p$ value \\
\hline $\begin{array}{l}\text { Proportion of respondents who "Always" and } \\
\text { "Usually" perform DRE on men for prostate } \\
\text { cancer screening. }\end{array}$ & $92.40 \%$ & $67.4 \%$ & $\begin{array}{l}\text { Chi-squared test } \mathrm{w} 1 \mathrm{df}= \\
16.874 \\
\mathrm{p}=0.000\end{array}$ \\
\hline $\begin{array}{l}\text { Proportion of respondents who begin screening } \\
\text { their male patients with DRE at age } 40 \text {. }\end{array}$ & $47.90 \%$ & $19.50 \%$ & $\begin{array}{l}\text { Chi-squared test } \mathrm{w} 1 \mathrm{df}= \\
27.248 \\
\mathrm{p}=0.000\end{array}$ \\
\hline $\begin{array}{l}\text { Proportion of respondents who begin screening } \\
\text { their male patients with DRE at age } 50 .\end{array}$ & $46.60 \%$ & $72.00 \%$ & $\begin{array}{c}\text { Chi-squared test } \mathrm{w} 1 \mathrm{df}= \\
19.995 \\
\mathrm{p}=0.000\end{array}$ \\
\hline $\begin{array}{l}\text { Proportion of respondents who feel PSA testing } \\
\text { is a valuable tool for prostate cancer screening. }\end{array}$ & $72.60 \%$ & $43.30 \%$ & $\begin{array}{l}\text { Chi-squared test } \mathrm{w} 1 \mathrm{df}= \\
35.641 \\
\mathrm{p}=0.000\end{array}$ \\
\hline $\begin{array}{l}\text { Proportion of respondents who believe DRE is } \\
\text { valuable for prostate cancer screening. }\end{array}$ & $90.80 \%$ & $63.90 \%$ & $\begin{array}{l}\text { Chi-squared test } \mathrm{w} 1 \mathrm{df}= \\
72.135 \\
\mathrm{p}=0.000\end{array}$ \\
\hline $\begin{array}{l}\text { Proportion of respondents believing there is } \\
\text { insufficient evidence to support PSA testing for } \\
\text { prostate cancer screening. }\end{array}$ & $33.80 \%$ & $49.40 \%$ & $\begin{array}{l}\text { Chi-squared test } \mathrm{w} 1 \mathrm{df}= \\
34.343 \\
\mathrm{p}=0.000\end{array}$ \\
\hline $\begin{array}{l}\text { Proportion of respondents believing there is } \\
\text { insufficient evidence to support DRE as part of } \\
\text { prostate cancer screening. }\end{array}$ & $8.20 \%$ & $32.50 \%$ & $\begin{array}{c}\text { Chi-squared test } \mathrm{w} 1 \mathrm{df}= \\
55.69 \\
\mathrm{p}=0.000\end{array}$ \\
\hline $\begin{array}{l}\text { Proportion of respondents, with over } 20 \text { years } \\
\text { experience, who "strongly disagreed" and } \\
\text { "disagreed" with the statement" PSA testing } \\
\text { leads to excessive ordering of subsequent } \\
\text { investigations (i.e., biopsies). }\end{array}$ & $48.80 \%$ & $26.10 \%$ & $\begin{array}{c}\text { Chi-squared test } \mathrm{w} 1 \mathrm{df}= \\
4.643 \\
\mathrm{p}=0.031\end{array}$ \\
\hline $\begin{array}{l}\text { Proportion of respondents who felt most } \\
\text { comfortable following the BCCA } \\
\text { guidelines/recommendations on prostate cancer } \\
\text { screening. }\end{array}$ & $39.4 \%$ & $25.3 \%$ & \\
\hline $\begin{array}{l}\text { Proportion of respondents who felt most } \\
\text { comfortable following the CTF } \\
\text { guidelines/recommendations on prostate cancer } \\
\text { screening. }\end{array}$ & $19.7 \%$ & $32.5 \%$ & \\
\hline $\begin{array}{l}\text { Proportion of respondents who felt most } \\
\text { comfortable following the CUA } \\
\text { guidelines/recommendations on prostate cancer } \\
\text { screening. }\end{array}$ & $7.0 \%$ & $15.7 \%$ & \\
\hline
\end{tabular}




\begin{tabular}{|c|c|c|c|}
\hline $\begin{array}{l}\text { Proportion of respondents who felt most } \\
\text { comfortable following "other" guidelines/ } \\
\text { recommendations on prostate cancer screening. }\end{array}$ & $1.4 \%$ & $6.0 \%$ & \\
\hline $\begin{array}{l}\text { Proportion of respondents who felt most } \\
\text { comfortable following no guidelines/ } \\
\text { recommendations on prostate cancer screening. }\end{array}$ & $24.0 \%$ & $12.0 \%$ & \\
\hline $\begin{array}{l}\text { Proportion of respondents who preferred } \\
\text { "other" or "none" as their initial screening tool } \\
\text { for prostate cancer screening. }\end{array}$ & $1.3 \%$ & $12.0 \%$ & $\begin{array}{c}\text { Chi-squared test for the } 5 \\
\text { proportions above } \\
\text { (combining with "other" } \\
\text { those guidelines not } \\
\text { considered above), w } 4 \mathrm{df}= \\
12.102 \\
\mathrm{p}=0.017\end{array}$ \\
\hline $\begin{array}{l}\text { Proportion of respondents who preferred DRE } \\
\text { and PSA in combination as their initial } \\
\text { screening tool for prostate cancer screening. }\end{array}$ & $59.5 \%$ & $48.2 \%$ & \\
\hline $\begin{array}{l}\text { Proportion of respondents who preferred DRE } \\
\text { or PSA in combination as their initial screening } \\
\text { tool for prostate cancer screening. }\end{array}$ & $40.5 \%$ & $39.8 \%$ & $\begin{array}{l}\text { Chi-squared test for the } 2 \\
\text { proportions above } \\
\text { (combining preference for } \\
\text { single DRE or PSA), w } 2 \mathrm{df} \\
=10.486 \\
\mathrm{p}=0.005\end{array}$ \\
\hline
\end{tabular}

BCCA: British Columbia Cancer agency; CTF: Canadian Task Force of Preventative Health Care; CUA: Canadian Urological Association; DRE: digital rectal exam; PSA: prostate-specific antigen. 